\title{
O Movimento Bibliográfico: organização do conhecimento no contexto da modernidade ${ }^{1}$
}

\author{
The bibliographic movement: knowledge organisation in the context of modernity
}

Luciana Corts Mendes

Doutoranda em Ciência da Informação pelo Programa de Pós-graduação em Ciência da Informação da Escola de Comunicações e Artes da Universidade de São Paulo - ECA/USP. E-mail: luciana.corts.mendes@usp.br

\section{Resumo}

Através de levantamento, revisão e análise bibliográficos, o artigo explora os objetivos e propostas de organização da informação desenvolvidos pelo Movimento Bibliográfico e indica sua influência na Ciência da Informação. O movimento caracterizava-se por sua pluralidade e buscava responder às alterações no mundo informacional decorrentes da modernidade. Apesar de sua especificidade histórica, esse movimento compartilha com a Ciência da Informação o ideário informacional moderno e a relação deste com a cultura. Conclui-se que a cultura da informação contemporânea e aquela do movimento pesquisado apresentam diferenças, porém se entrelaçam.

Palavras-chave: História da Ciência da Informação. Movimento bibliográfico. Modernidade.

\begin{abstract}
Through bibliographic survey, literature review, and analysis, the article explores the objectives and proposals of information organisation developed by the Bibliographic Movement and indicates its influence in Information Science. The movement was characterised by its plurality and aimed to respond to modernity's effects in the information world. Despite its historical specificity, this movement shares with Information Science modern ideas and their relation to culture. It is concluded that the current information culture and the information culture of the movement have differences, notwithstanding, they are entwined.
\end{abstract}

Keywords: Information Science history. Bibliographic Movement. Modernity.

\footnotetext{
${ }^{1} \mathrm{O}$ artigo é resultante da pesquisa de mestrado da autora, que foi apoiada financeiramente com bolsa de mestrado pela FAPESP (bolsa referente ao processo 2012/09084-0).
}

InCID: R. Ci. Inf. e Doc., Ribeirão Preto, v. 7, n. esp., p. 134-151, ago. 2016. 


\section{Introdução}

A modernidade afetou profundamente o mundo informacional. As práticas relativas à produção, circulação e consumo da informação foram fundamentalmente modificadas por diversos fatores, dos quais podemos destacar: as transformações no processo de geração de conhecimento; as novas práticas de organização da sociedade com base na racionalização e no controle; e as novas tecnologias de registro do conhecimento, ou, nas palavras de Rayward (2008, p. 4), a proliferação dos sistemas de publicação, tais como a aplicação do motor a vapor à tipografia; o desenvolvimento de novas máquinas tipográficas; e a criação de tecnologias que permitiam registros cinematográficos, fotográficos e sonoros. Essas alterações levaram a um aumento exponencial na produção de informação, aumento este que Schneiders (2012a, p. 43) afirma ter impactado diferentemente os diversos estratos da sociedade; entretanto, as dificuldades que se seguiram a esse impacto apresentavam um traço comum: a informação disponível era maior do que a capacidade humana de organizá-la para torná-la acessível. Consequentemente, a sociedade estabeleceu um novo tipo de relação com a informação e, portanto, torna-se imprescindível a adaptação do aparelho bibliográfico por meio de novos métodos de gestão dos recursos informacionais. Para responder a essa nova conjuntura, surge no final do século XIX o Movimento Bibliográfico.

O Movimento Bibliográfico não resultou unicamente de uma “explosão informacional”. Como afirma Schneiders (1982, 2012a), a busca e o uso da informação estavam relacionados a questões diversas de caráter tanto quantitativo como qualitativo, de modo que o movimento deve ser analisado como um evento cultural-histórico que se relaciona às crises que ocorreram na ciência por volta de 1880. Alinhamo-nos ao entendimento de Schneiders, concluindo que o Movimento Bibliográfico é resultante de diversas circunstâncias e não somente do aumento da quantidade de documentos existente, de modo que procuramos compreender esse fenômeno através de sua contextualização cultural e histórica. Não obstante, consideramos o movimento como resultante não apenas do que ocorreu no domínio da ciência no final do século XIX, mas sim como o resultado do desenrolar da própria modernidade e de suas consequências.

Destarte, apresentaremos neste artigo uma análise contextual cultural e histórica do Movimento Bibliográfico e de sua herança para a Ciência da Informação. 


\section{Um breve panorama da modernidade}

No século XVII surge na Europa uma nova concepção de vida resultante do advento de novas ideias, atitudes e técnicas que cingiram a organização intelectual, social e política: a modernidade (GIDDENS, 1991; HALL, 1992; KUMAR, 2006). Ortiz (1991, p. 263) assim define este fenômeno: "a modernidade é um modo de ser, uma sensibilidade. Em termos antropológicos eu diria, ela é uma cultura, uma visão de mundo com suas próprias categorias cognitivas".

A modernidade é caracterizada pela centralidade da ideia de que os sentidos humanos são limitados e, portanto, insuficientes para o conhecimento pleno do mundo. Dessa constatação conclui-se que somente o pensamento apresenta certeza em si mesmo, de modo que a capacidade de dedução e conclusão da mente humana, a razão, torna-se o referencial do conhecimento (ARENDT, 1998; BRUBAKER, 1984; MATTELART, 2006; SANTOS, 2010).

Assim, conhecer significa produzir os fenômenos e objetos que se deseja observar, ou seja, os dados obtidos através dos sentidos são submetidos às capacidades de compreensão da mente, o que permitiria uma observação do mundo distanciada e objetiva (ARENDT, 1998; BRUBAKER, 1984; SANTOS, 2010). Com isso, a experimentação se torna o modo padrão de conhecimento da natureza, pois através dos experimentos os fenômenos naturais externos à mente podem ser dominados, imitados e submetidos à mente (ARENDT, 1998; SANTOS, 2010).

O caráter processual do modo moderno de conhecer se torna central à sensibilidade moderna, a ele subjazendo a metáfora da fertilidade natural da vida, uma atividade sem fim que responde às suas próprias leis e que independe da vontade humana. Há assim a glorificação do processo biológico através da conclusão de que a própria sociedade é por ele dominada (ARENDT, 1998).

Dessa concepção é modificada a natureza do trabalho humano, ou seja, a produção de bens e serviços, pois esse passa a ser considerado mais uma parte do processo biológico humano. Assim, as ferramentas "perdem” seu caráter instrumental e "desaparece" a distinção entre o homem e seus utensílios, o ritmo mecânico substituindo o ritmo corporal natural (ARENDT, 1998; HARVEY, 2011). Desse modo, “a imagem da máquina, constituída por diversas peças engrenadas entre si, aos poucos se impõe" (ORTIZ, 1991, p. 205), o que leva o mundo a ser visto de maneira mecanicista. 
Subsequentemente o industrialismo se instala e dá à modernidade uma forma material, sem a qual ela não poderia se expressar. Muito mais do que um sistema de produção ou um sistema econômico, o industrialismo permeia toda a sociedade moderna (CANOVAN, 1998; GIDDENS, 1991; KUMAR, 2006; ORTIZ, 1991).

Enquanto o industrialismo embasa materialmente a modernidade, o Iluminismo a fundamenta filosoficamente. Crítico da autoridade tradicional e tendo como condutoras as ideias de progresso, ciência, razão e natureza, o Iluminismo rompe com a história e a tradição. A partir de então a vida humana deveria orientar-se por seu projeto de futuro e não mais pela autoridade do passado, com vistas a, por meio da difusão da cultura e do saber, dar início a uma era de prosperidade e progresso material, onde justiça, moral e sociedade seriam aperfeiçoadas e em última instância a felicidade humana aumentaria (HABERMAS, 1981; HALL, 1992; HAMILTON, 1992; HARVEY, 2011; TODOROV, 2008). Os objetivos iluministas seriam atingidos por meio de previsão científica, engenharia social, planejamento racional e institucionalização de sistemas racionais de regulação e controle social, inclusive através da ordenação racional do espaço e do tempo (HARVEY, 2011).

O panorama anteriormente descrito dá origem ao cientificismo, "uma doutrina filosófica e política [...] que parte da premissa de que o mundo é inteiramente passível de conhecimento; então passível de transformação de acordo com os objetivos que nos colocamos, objetivos deduzidos eles próprios diretamente desse conhecimento do mundo" (TODOROV, 2008, p. 88); ou seja, a modernidade impõe um modelo global de racionalidade pautado na ciência (SANTOS, 2010).

Dessa conjuntura é originada uma das consequências substanciais da modernidade, a globalização, que cria uma interdependência mundial e uma consciência planetária (GIDDENS, 1991; HOBSBAWM, 2009; ORTIZ, 1991). Um mundo cada vez mais dependente exige sua racionalização, ideia central da modernidade.

A organização racional era considerada o meio por excelência de realização de todos os objetivos aos quais o homem se propunha, pois nela há a centralidade da ação, ou seja, o homem deve lutar pró ativamente pelo entendimento e controle racional de todos os seus interesses (BARBER, 1964; HARVEY, 2011). É assim que é possível a Habermas (2006) afirmar que racionalização significa uma ampliação das esferas sociais submetidas a critérios racionais de decisão, implantando a ação racional direcionada a fins. Com a institucionalização dos progressos científico e técnico, a ciência passa a ser vista como a forma mais objetiva de se 
O Movimento Bibliográfico: organização do conhecimento no contexto da modernidade

determinar o modo mais racional através do qual se deve atingir um determinado objetivo (BRUBAKER, 1984; HABERMAS, 2006).

Segundo Barber (1964) eficiência e ordem são os sinais externos da racionalidade. O propósito da atividade de organização, uma atividade racional direcionada a fins, é o controle. Desse modo, o objetivo da modernidade era o controle do mundo. Contudo, controle deve aqui ser entendido como uma influência proposital em direção a um objetivo predeterminado, não como um domínio ou poder absoluto sobre algo. Nesta acepção, controlar significa a capacidade humana de se adaptar ao mundo exterior, adaptar culturalmente as circunstâncias às suas conveniências (BENIGER, 1986; HABERMAS, 2006).

Toda a sociedade fora tragada pela modernidade e sua sensibilidade, o mundo informacional não se constituindo como exceção. A visão de mundo moderna e suas categorias cognitivas se infiltraram no mundo informacional, sendo a este necessário se adaptar culturalmente às novas circunstâncias de modo a que suas necessidades fossem atendidas. Assim surge o Movimento Bibliográfico.

\section{O Movimento Bibliográfico}

O Movimento Bibliográfico objetivava responder às transformações que a modernidade impôs ao mundo informacional. Formado por diversos indivíduos, tais como cientistas, pesquisadores, bibliotecários e bibliógrafos (SANTOS, 2006, p. 1), o movimento não era uma ação sistematizada composta por um grupo coeso de pessoas trabalhando em conjunto; na realidade, nas palavras de Schneiders (2012a, p. 39), o Movimento Bibliográfico tratava-se de uma unidade formada na diversidade.

Com a modernidade surge um novo entendimento de informação onde, de acordo com Muddiman (1998), um conceito estático de conhecimento e livros dá lugar a um discurso cinético de informação, comunicação e mercadoria. Esse novo entendimento fez com que os diversos aspectos do mundo informacional e de sua infraestrutura social fossem observados e analisados de novas maneiras, o que culminou em: difusão de novas ideias; identificação de novos fenômenos; mudança nas práticas linguísticas com a criação de nova terminologia; criação de novas estruturas formais de comunicação interpessoal; e desenvolvimento de novas ferramentas e técnicas para o tratamento da informação (RAYWARD, 1997). 
Em decorrência dessa nova conjuntura, os métodos existentes de organização da informação não eram mais capazes de atender às necessidades informacionais, não por sua nulidade, mas sim por não mais se adequarem às novas exigências informacionais (SCHNEIDERS, 2012a).

Em função de suas diferentes práticas de conhecimento e pesquisa, as necessidades informacionais das humanidades eram diferentes daquelas das ciências naturais. De modo geral os recursos informacionais são fontes primordiais nas práticas das humanidades, enquanto que nas ciências naturais os processos experimentais são a principal fonte de informação, a bibliografia complementando as atividades realizadas em campo ou em laboratório. Assim, as novas necessidades das humanidades levaram a discussões sobre a formação de coleções, a melhoria dos catálogos e a necessidade de maiores espaços; já as ciências naturais buscavam responder tanto às questões anteriores, como também solucionar questões relativas à velocidade e eficiência na transmissão do conhecimento; à variedade de documentos; e à disseminação seletiva, uma vez que com o aumento gradativo da centralidade da ciência na sociedade moderna, o conhecimento técnico especializado era cada vez mais demandado (SHERA; EGAN, 1953; SCHNEIDERS, 1982, 2012a, 2012b).

As diferentes necessidades informacionais das humanidades e das ciências naturais levaram à divergência entre as áreas sobre como a informação deveria ser tratada, afinal "peculiaridades especiais de natureza ou circunstância fazem com que métodos apropriados em um ramo do conhecimento [sejam] inaplicáveis em outro"2 (JENKINSON ${ }^{3}$ apud MUDDIMAN, 2013, p. 390). Schneiders (2012b, p. 40) assim sintetiza a conjuntura: "havia divergência não somente entre explorar e conservar, mas também entre tipos de documentos, tipos de uso, formas de uso e talvez até entre tipos humanos que encontram satisfação em conservação ou em exploração".

A nova consciência informacional não se restringiu às áreas diretamente dependentes da ciência. Bibliotecas foram criadas em empresas e serviços administrativos, principalmente nas áreas de política econômica, comércio, indústria e agricultura. Desse modo surgiram a biblioteca especializada, a unidade de informação, o serviço de informação e o serviço de documentação, assim chamados de modo a enfatizar a informação per se, que passara a ser

\footnotetext{
${ }^{2}$ As traduções dos textos em outros idiomas são de nossa responsabilidade.

${ }^{3}$ JENKINSON, H. Archives in their relation to other forms of documentation. In: XIV ${ }^{\mathrm{TH}}$ CONFERENCE OF THE INTERNATIONAL FEDERATION FOR DOCUMENTATION, 1938, Oxford-London. Transactions... The Hague: FID, 1938. p. C11-15.
} 
organizada com maior refinamento e levou à especialização profissional (BLACK, 2001; CABRALES; LINARES, 2005; MUDDIMAN, 1998; SCHNEIDERS, 2012a, 2012b).

A seguir exploraremos a perspectiva de tratamento da informação das ciências naturais, resultado da análise do pensamento de cinco expoentes do Movimento Bibliográfico - Paul Otlet (1868-1944), Wilhelm Ostwald (1853-1932), H. G. Wells (1866-1946), John Cotton Dana (1856-1929) e Watson Davis (1896-1967) - que realizamos em nossa pesquisa de mestrado (MENDES, 2014) $)^{4}$

\section{A perspectiva das ciências naturais no Movimento Bibliográfico}

Todas as propostas de organização da informação analisadas em nossa pesquisa (MENDES, 2014) tinham como objetivo organizar a informação para que esta fosse recuperada e acessada pela sociedade, de maneira a cumprir a função que lhe fora atribuída.

Todos os indivíduos analisados atribuíam à informação a função de transformação das condições humanas uma vez que ela fosse apropriada. Isso ocorreria porque as ideias registradas nos recursos informacionais teriam a potencialidade de transformar o indivíduo que as apropriasse, permitindo a este interferir em suas esferas de vivência, auxiliando na resolução de problemas profissionais e científicos e, em última instância, levando ao progresso coletivo, à construção de uma sociedade melhor e à paz mundial.

Essa crença é típica da modernidade, onde o racionalismo crítico associado à difusão do saber seria responsável pela prosperidade e pelo progresso, tanto material como moral. Ademais, a interdependência mundial ocorrida no seio da modernidade e os movimentos do internacionalismo e da cooperação internacional dela nascidos subjazem à ideia de que a informação permitiria a reconciliação e harmonização de povos, sua unificação intelectual e o estabelecimento de uma civilização mundial dotada de uma cultura universal.

Para que a informação pudesse cumprir essa função era necessário acessá-la. Assim, a nova consciência informacional levou ao fim da sacralização dos recursos informacionais enquanto unidades físicas, transformando o caráter fundamental de custódia dos serviços de

\footnotetext{
${ }^{4}$ Em função das limitações impostas pelo formato do artigo acadêmico, não apresentaremos as ideias e análises de cada um dos indivíduos investigados em nossa pesquisa de mestrado. Como o objetivo de nossa pesquisa era a compreensão do Movimento Bibliográfico enquanto fenômeno geral, neste artigo expomos o movimento em si. As análises individuais, bem como a lista completa dos trabalhos revisados e analisados, de autoria dos sujeitos selecionados, podem ser encontradas em nossa dissertação de mestrado.
} 
informação, de modo que a acessibilidade ao conteúdo dos registros de conhecimento tornouse primordial.

É a função atribuída à informação pelo Movimento Bibliográfico que leva à mudança da ênfase da preservação para o acesso. O foco no conteúdo e não no artefato contentor acaba com a ideia de que formato livro seria intrinsecamente superior; todos os tipos de registro seriam então dotados da mesma capacidade informativa. Concluímos que a mudança de uma perspectiva de conservação para uma perspectiva de utilização está relacionada à centralidade do processo biológico na modernidade, especificamente o processo duplo de metabolismo do corpo humano. $\mathrm{Na}$ abordagem moderna os documentos não são apenas utilizados, mas sim consumidos. As características de renovação e fertilidade são assim inseridas nos serviços de informação, de modo que agora estes também são "organismos vivos" capazes de interferir diretamente na sociedade.

O consumo dos documentos, que levaria ao cumprimento da função atribuída à informação pelo Movimento Bibliográfico, dependia não apenas da disponibilidade física desses registros, mas também das capacidades cognitivas individuais. Para os expoentes do Movimento Bibliográfico somente através da acessibilidade física $e$ intelectual aos recursos informacionais é que a informação poderia cumprir sua função. O acesso ao conhecimento registrado dependia da organização da informação, pois somente estando organizada ela podia ser recuperada e assimilada.

Destarte, a organização da informação não era um fim em si mesmo para o Movimento Bibliográfico, mas sim um meio através do qual se permitia o acesso à informação para que esta cumprisse sua função. O objetivo da existência de serviços de informação era que esta fosse apropriada, de maneira a alterar e, portanto, melhorar a sociedade; assim, o movimento se direciona para a organização dos registros do conhecimento não de acordo com sua fisicalidade, mas sim de acordo com seu conteúdo. Por essa razão, a informação documentária se torna fundamental.

Resumos, índices e sistemas de classificação eram os principais meios apregoados pelo movimento para a organização da informação para que esta fosse recuperada fácil e agilmente. As classificações decimais eram recomendadas por sua expansibilidade, flexibilidade e universalidade, características que aumentariam a eficiência tanto da organização física de acervos como dos catálogos de ficha, uma vez que possibilitavam tanto a fácil intercalação de documentos como de fichas. Outra característica frequentemente exaltada desse tipo de 
classificação era o fato de serem representadas com números arábicos, o que permitiria a padronização mundial dos catálogos, e, portanto, a recuperação da informação por qualquer pessoa independentemente dos idiomas que dominasse.

A criação de catálogos de ficha tornou-se indispensável nessa nova conjuntura informacional, pois se tratava de uma tecnologia bastante prática que permitia uma recuperação rápida. O movimento recomendava que fossem produzidos ao menos dois catálogos por serviço de informação, um organizado por assuntos e outro organizado alfabeticamente pelos autores das obras. Dessa maneira, os pontos de acesso à informação seriam ampliados, proporcionando mais opções de busca e, consequentemente, de recuperação da informação.

É relevante destacarmos que a elaboração de resumos, índices e catálogos não surgiram com o Movimento Bibliográfico, eram atividades pré-existentes que foram racionalizadas para atender às novas demandas informacionais.

Aquilo que o Movimento Bibliográfico realmente introduziu no processo de organização da informação foi atividade de seleção. Apesar de este não ser um conceito originado com o movimento, é a partir deste que a seleção se populariza e se torna prática corrente nos serviços de informação. Os expoentes do movimento frequentemente enfatizavam o fato de que a capacidade humana de apropriação da informação não aumentara proporcionalmente ao aumento do número de publicações, sendo necessário, como dizia Otlet (2007, p. 373-373 bis), "ordenar 'montanhas' de papéis e documentos", de maneira que "criar uma 'metalurgia' do papel, fazer galerias de aproximação a estas montanhas, cheias de tesouros, extrair o bom mineral para separar em seguida o metal puro da ganga" se tornara indispensável.

No entanto, o Movimento Bibliográfico não estabeleceu critérios para a elaboração de informação documentária. É frequentemente reiterado o que se devia fazer, contudo o como nunca foi elaborado.

As propostas elaboradas pelo movimento foram formuladas com vistas a que houvesse a máxima economia de dinheiro, energia e tempo dos indivíduos que buscavam informação; ou seja, eram orientadas pela lógica da sociedade moderna, sendo entendidas de maneira análoga ao processo biológico vital e tendo subjacentes ideias mecanicistas, industrialistas e as concepções de espaço e de tempo modernas. Desse modo, entendia-se que as atividades de organização da informação requeriam organização e racionalização, devendo ser realizadas de acordo com os princípios da modernidade. 
Se a organização era fundamental para o acesso à informação, somente por meio da disseminação a informação podia cumprir sua função de transformação dos indivíduos. Portanto, para o Movimento Bibliográfico era imprescindível a disseminação da informação e diversas foram suas propostas para a mesma. A principal ideia comum entre os expoentes do movimento era o estabelecimento de redes de instituições com o propósito de realização de atividades cooperativas e compartilhamento de acervos. A criação dessas redes permitiria que todo o conhecimento fosse disseminado para todo o mundo.

O grande desenvolvimento tecnológico moderno fez com que os expoentes do Movimento Bibliográfico enfatizassem a aplicação das novas tecnologias ao processo de disseminação da informação, pois entendiam que este seria facilitado e agilizado através das mesmas. Essas tecnologias levaram à elaboração de propostas de máquinas que permitiriam o acesso imediato a todos os documentos do mundo; entretanto, aquelas não passaram de meros projetos conceituais.

Meios mais convencionais de disseminação também foram propostos, levando a discursos em prol do estabelecimento de bibliotecas públicas, do barateamento de livros e da popularização da ciência por meios impressos de massa.

É possível que os expoentes do Movimento Bibliográfico tenham se influenciado mutuamente, entretanto, não é possível descartar a ideia de que o Zeitgeist comum tenha dado origem a propostas e conclusões similares. Destarte, concluímos que mesmo sem um reconhecimento formal das ideias de outrem, o pensamento de cada expoente do movimento pode ter sofrido influência das ideias de seus pares. Esta explicação por si só, contudo, não basta, já que o espírito do tempo compartilhado por esses indivíduos levou ao estabelecimento de um ideário comum, portanto, a explicação mais plausível para as similaridades verificadas é a combinação da influência mútua e de uma conjuntura cultural e histórica comum.

Destarte, concordamos com Day (2001b, p. 727) que "uma história completa da gestão do conhecimento deve levar em consideração os fundamentos históricos, sociais e culturais, assim como os desenvolvimentos tecnológicos e objetivos para a representação do pensamento e da vida dentro de seu contexto de produção". Ou seja, "foi dentro do contexto da cultura 'científica' da modernidade que a Documentação [e por extensão todo o Movimento Bibliográfico] pode ser entendida não como uma simples técnica bibliográfica, mas como uma técnica cultural" (DAY, 2001a, p. 7-8). 
O movimento que era desprovido de uma organização coesa acabou por originar duas novas disciplinas: a Biblioteconomia Especializada e a Documentação. A natureza fragmentada do Movimento Bibliográfico levou ao desenvolvimento de duas disciplinas diferentes que estiveram frequentemente em atrito tanto nos Estados Unidos como na Europa ${ }^{5}$. Apesar dos conflitos, sempre houve uma grande correspondência entre a Biblioteconomia Especializada e a Documentação, que faziam uso basicamente dos mesmos métodos para organizar e disponibilizar a informação, ambas priorizando a informação per se independentemente do suporte no qual estava registrada. Diversos autores da Ciência da Informação detectaram essas similaridades, como Schneiders (2012a), Shera (1952) e Williams (1997), além de importantes documentalistas contemporâneos aos embates descritos, como Suzanne Briet e Frits Donker Duyvis (ORTEGA, 2009a, p. 10, 2009b, p. 65; WILLIAMS, 1997, p. 777).

Biblioteconomia Especializada e Documentação são consideradas como raízes da Ciência da Informação, no entanto, o movimento legou à Ciência da Informação muito mais do que essas disciplinas. Isto posto, apresentaremos a seguir a herança do Movimento Bibliográfico para a Ciência da Informação.

\section{A herança do Movimento Bibliográfico para a Ciência da Informação}

Como acima explicitado, o Movimento Bibliográfico é um fenômeno fundamentalmente moderno, mas sua relevância permanece, já que a maior parte das preocupações que deram origem a esse movimento ainda são de preocupação da sociedade contemporânea.

A Ciência da Informação objetiva "a formulação de sistemas significantes dos conteúdos registrados para fins de recuperação da informação" (TÁLAMO; SMIT, 2007, p. 41), ou seja, a área busca criar sistemas de recuperação da informação documentada, objetivo compartilhado pelo Movimento Bibliográfico.

A informação documentada com a qual a Ciência da Informação trabalha pressupõe o registro do conhecimento, independentemente do suporte no qual o conhecimento foi registrado e do tipo de registro. Como visto anteriormente, é durante a modernidade que o livro passa a

\footnotetext{
${ }^{5}$ Curiosamente a Biblioteconomia Especializada e a Documentação se desenvolveram sem rivalidades na Inglaterra, fortalecendo-se mutuamente e atuando em parceria (BLACK; MUDDIMAN, 2007, p. 42-43; LAQUA, 2013, p. 468; RAYWARD, [1983], p. 348; ROBINSON; BAWDEN, 2013).
} 
não atender mais a todas as necessidades informacionais da sociedade, de modo que o Movimento Bibliográfico passa a reconhecer outras formas de registro do conhecimento. Assim, concluímos que a ampliação da esfera de validade dos formatos documentários é um legado do Movimento Bibliográfico para a Ciência da Informação.

Essa ampliação por parte do movimento originou-se da função que atribuíam à informação, ou seja, sua capacidade de transformação das condições humanas uma vez que fosse apropriada. Esta ideia sobrevive nas teorias e práticas da Ciência da Informação, que objetiva a organização dos registros do conhecimento com vistas à "melhoria das condições de vida do homem e da sociedade através do acesso à informação" (SMIT, 2012, p. 99). Apesar de as propostas do Movimento Bibliográfico visarem uma transformação utópica das condições humanas, o movimento lega à Ciência da Informação a ideia de que a gestão de um serviço de informação pressupõe uma orientação clara em direção à esfera de vida que o conteúdo de seu acervo busca auxiliar.

O auxílio à melhora das condições humanas e sociais somente é viabilizado se a informação estiver reunida e organizada dentro de um serviço de informação. Destarte, a construção de estoques informacionais pressupõe a seleção, reunião, redução, codificação, classificação e armazenamento de informação. Estas são atividades de organização e controle dos acervos e até hoje conceitos e práticas de organização e controle formulados e iniciados com o Movimento Bibliográfico se apresentam no atual ideário da Ciência da Informação.

Para a Ciência da Informação, quando uma informação é selecionada para compor um estoque informacional ela é intencionalmente preservada em função de um "poder informacional", ou seja, de sua potencial utilidade. Este poder é relativo e determinado histórica e culturalmente, de modo que a seleção não é um processo neutro. O "poder informacional” era igualmente reconhecido pelo movimento que analisamos, contudo, o processo de atualização de um estoque informacional não era univocamente compreendido pelos expoentes analisados.

A atualização de um serviço de informação podia ser unicamente a inserção de nova informação nesse serviço, pois seria possível determinar a informação eternamente útil e somente esta seria armazenada, ou então esse processo poderia também requerer o descarte dos conteúdos que perderam seu "poder informacional". Assim, havia quem acreditasse na possibilidade de uma seleção neutra e plena e aqueles que entendiam a seleção como relativa e desprovida de neutralidade. Portanto, o Movimento Bibliográfico lega à Ciência da Informação tanto a ideia da potencial utilidade informacional, como a preeminência do processo de seleção 
O Movimento Bibliográfico: organização do conhecimento no contexto da modernidade

- neste último caso alguns de seus expoentes também legaram à disciplina os conceitos de relatividade e ausência de neutralidade no processo de seleção.

Para a Ciência da Informação, uma vez selecionados e reunidos, os recursos informacionais precisam ser reduzidos, codificados e classificados. Ou seja, é necessário elaborar a informação documentária que dá origem a catálogos e bases de dados e que permite a recuperação futura da informação. Esse era o mesmo credo do Movimento Bibliográfico, contudo o movimento não deixa um forte legado nesta subárea da Ciência da Informação, pois aquilo que propunha como informação documentária, os resumos, índices e sistemas de classificação, eram a ele pré-existentes e foram apenas modificados para atender às novas necessidades informacionais. Ademais, nenhum dos indivíduos analisados estabeleceu critérios para a elaboração de informação documentária. Para um movimento tão preocupado com a capacidade de recuperação da informação, ele dedicava pouquíssima atenção à metodologia de elaboração de informação documentária, a informação mediadora entre estoque e usuário.

Para o Movimento Bibliográfico as atividades envolvidas na criação de estoques informacionais deveriam obedecer a um conjunto de princípios característicos da modernidade: cooperação, coordenação, normalização, padronização, racionalização, seriação de esforços, unidade e uniformidade. Esta é mais uma herança do movimento para a Ciência da Informação, uma vez que esta continua a ter estes princípios em seu cerne.

O objetivo final da Ciência da Informação é que ocorra a transferência do conteúdo registrado em um documento para quem o utiliza. Essa transferência ocorre quando os estoques de informação são acessados e utilizados, podendo potencialmente contribuir para o conhecimento daqueles que se apropriam da informação. Acesso indica uma operação físicoespacial e transferência pressupõe atividades cognitivas subjetivas.

Como visto anteriormente, a acessibilidade era central para o Movimento Bibliográfico, bem como a adequação dos recursos informacionais às capacidades cognitivas individuais. Para o movimento tanto operações físico-espaciais como atividades cognitivas subjetivas eram necessárias para que houvesse a apropriação da informação. Portanto, ainda que as concepções do Movimento Bibliográfico e da Ciência da Informação sejam divergentes com relação à natureza do processo cognitivo essencial à transferência da informação, há um componente de atividade mental nos conceitos de ambos sobre a apropriação da informação, o que pode indicar a influência do movimento na Ciência da Informação.

InCID: R. Ci. Inf. e Doc., Ribeirão Preto, v. 7, n. esp., p. 134-151, ago. 2016. 
O acesso à informação depende da disseminação da mesma, assim o Movimento Bibliográfico formulou propostas de redes cooperativas para empréstimo de documentos entre bibliotecas; fez planos de utilização do microfilme - a tecnologia preferida do movimento como meio de registro, disseminação e armazenamento da informação; e imaginou máquinas que permitiriam a recuperação da informação remotamente. Redes cooperativas continuam a ser fundamentais para a disseminação da informação, principalmente com o uso crescente da internet; o microfilme teve um grande uso nos serviços de informação, apesar de ter sido substituído por tecnologias mais eficientes e eficazes; e atualmente diversos dispositivos eletrônicos celulares permitem o acesso remoto à informação. Estes aspectos indicam algum tipo de herança do Movimento Bibliográfico para a Ciência da Informação?

Os expoentes do Movimento Bibliográfico são constantemente chamados de visionários na literatura da Ciência da Informação; não obstante, é necessária cautela quando ideias passadas relativas ao mundo informacional são comparadas às contemporâneas. São dignas de nota as similaridades entre aquilo que o movimento concebeu e as atuais concepções do mundo informacional; contudo, nossa análise não nos permite afirmar que os indivíduos investigados eram visionários. Os expoentes do Movimento Bibliográfico estavam inseridos no contexto da modernidade e suas propostas refletem o pensamento do período. Este ideário ainda subjaz às atuais propostas de organização da informação para seu acesso e uso, apesar de não se limitar a ele, pois, como afirma Day (2001a), as abordagens informacionais são tanto constituintes como constituídas por histórias culturais.

Segundo Day (2001a, p. 8) é importante não somente analisar uma obra deste período por sua influência histórica nos desenvolvimentos posteriores da tecnologia da informação e da Ciência da Informação, mas também como "sintomas do nascimento de uma cultura da informação" (grifo nosso). Apesar de sua especificidade histórica, o Movimento Bibliográfico compartilha com a Ciência da Informação o ideário moderno referente à informação e ao relacionamento desta com a cultura. A atual cultura da informação pode não ser um espelho da cultura da informação do movimento que analisamos, mas são culturas que se entrelaçam. Com a identificação daquilo que a Ciência da Informação herdou do Movimento Bibliográfico são perceptíveis os pontos em que compartilham uma mesma cultura informacional; como afirma Day (2001a, p. 12-13), “as histórias do livro e da informação não são continuas e tampouco são descontinuas, em vez disto elas formam uma linha de significado histórico que molda a tradição da cultura da informação". 
É levando isto em consideração que a Ciência da Informação pode construir seu corpo teórico e desenvolver sua epistemologia.

\section{Conclusão}

A modernidade transformou o mundo de inúmeras maneiras, inclusive o mundo informacional. O Movimento Bibliográfico surgiu no seio da modernidade, constituindo-se como uma tentativa de organização da informação para que a sociedade pudesse acessá-la e utilizá-la em uma conjuntura informacional totalmente nova. Um novo contexto com novas necessidades pedia novas metodologias de organização da informação, portanto, ascendem um novo pensamento informacional e uma nova cultura informacional fundamentalmente modernos.

A apropriação crítica do pensamento informacional do Movimento Bibliográfico permitiu compreender suas propostas de organização da informação; de que maneira essa abordagem informacional é característica de seu tempo; e identificar seu legado para a Ciência da Informação. A identificação da herança do Movimento Bibliográfico para a Ciência da Informação e a adoção de uma perspectiva de progressão histórica permite que entendamos quem somos enquanto área, à qual cultura informacional pertencemos e como desenvolver a Ciência da Informação. 


\section{Referências}

ARENDT, H. The human condition. 2. ed. Chicago: Chicago University Press, 1998.

BARBER, B. Science in modern society: its place in liberal and in authoritarian society. In: MARSAK, L. M. (Ed.). The rise of science in relation to society. New York: Macmillan, 1964. (Main Themes in European history). p. 122-133.

BENIGER, J; R. The control revolution: technological and economic origins of the information society. Cambridge, MA: Harvard University Press, 1986.

BLACK, A. The Victorian information society: surveillance, bureaucracy, and public librarianship in 19th-century Britain. The information society, [New York], v. 17, n. 1, p. 63-80, 2001.

BLACK, A.; MUDDIMAN, D. The information society before the computer. In: ; PLANT, H. The early information society: information management in Britain before the computer. Aldershot: Ashgate e-Book, 2007. p. 3-50.

BRUBAKER, R. The limits of rationality: an essay on the social and moral thought of Max Weber. London: Routledge, 1984.

CABRALES HERNÁNDEZ, G.; LINARES COLUMBIÉ, R. Origen y formación de la ciencia de la información (1895-1962). Biblios, [Lima], v. 6, n. 21-22, p. 84-98, 2005.

CANOVAN, M. Introduction. In: ARENDT, H. The human condition. 2. ed. Chicago: Chicago University Press, 1998.

DAY, R. E. The modern invention of information: discourse, history, and power. Carbondale: Southern Illinois University Press, 2001a.

. Totality and modernity. Journal of the American Society for Information Science, [New York], v. 52, n. 9, p. 725-734, 2001 b.

GIDDENS, A. As consequências da modernidade. São Paulo: Editora Unesp, 1991.

HABERMAS, J. Modernity versus postmodernity. New German Critique, [New York], n. 22, Special Issue on Modernism, p. 3-14, 1981.

Técnica e ciência como <<ideologia>>. In: Técnica e ciência como “ideologia". Lisboa: Edições 70, 2006. (Biblioteca de filosofia contemporânea, 3). p. 45-92.

HALL, S. Introduction. In: .; GIEBEN, B. (Ed.). Formations of modernity. Oxford: Polity in association with Open University, 1992. p. 1-16.

HAMILTON, P. The Enlightenment and the birth of social science. In: HALL, S.; GIEBEN, B. (Ed.). Formations of modernity. Oxford: Polity in association with Open University, 1992. p. 17-69. 
HARVEY, D. Condição pós-moderna: uma pesquisa sobre as origens da mudança cultural. 21. ed. São Paulo: Loyola, 2011.

HOBSBAWM, E. J. A era do capital: 1848-1875. 14. ed. Rio de Janeiro: Paz \& Terra, 2009.

KUMAR, K. Da sociedade pós-industrial à pós-moderna: novas teorias sobre o mundo contemporâneo. 2. ed. ampl. Rio de Janeiro: Jorge Zahar, 2006.

LAQUA, D. Intellectual exchange and the new information order of the interwar years: the British Society for International Bibliography, 1927-1937. Library Trends, [Urbana], v. 62, n. 2, p. 465-477, 2013.

MATTELART, A. História da sociedade da informação. 2. ed. rev. atual. São Paulo: Loyola, 2006.

MENDES, L. C. Do tecer do algodão ao tecer da informação: organizando a explosão informacional do século XIX. 2014. 240 f. Dissertação (Mestrado em Ciência da Informação) - Escola de Comunicações e Artes, Universidade de São Paulo, São Paulo, 2014.

MUDDIMAN, D. Documentation under duress: the joint conference of the International Federation for Information (FID) and the Association of Special Libraries and Information Bureaux (ASLIB), Oxford-London, 1938. Library Trends, [Urbana], v. 62, n. 2, p. 378-401, 2013.

The universal library as modern utopia: the information society of H. G. Wells. Library History, [London], v. 14, n. 2, p. 85-101, 1998.

ORTEGA, C. D. A Documentação como uma das origens da Ciência da Informação e base fértil para sua fundamentação. Brazilian Journal of Information Science, [Marília], v. 3, n. 1, p. 3-35, 2009a.

Surgimento e consolidação da documentação: subsídios para compreensão da história da Ciência da Informação no Brasil. Perspectivas em Ciência da Informação, Belo Horizonte, v. 14, número especial, 59-79, 2009 b.

ORTIZ, R. Cultura e modernidade: a França no século XIX. São Paulo: Brasiliense, 1991.

OTLET, P. El tratado de documentación: el libro sobre el libro: teoría y práctica. 2. ed. Murcia: Universidad de Murcia, 2007.

RAYWARD, W. B. Introduction. In: (Ed.). European modernism and the information society: informing the present, understanding the past. Aldershot: Ashgate, 2008. p. 1-25.

Library and Information Sciences: disciplinary differentiation, competition, and convergence. In: MACHLUP, F.; MANSFIELD, U. (Ed.). The study of information: interdisciplinary messages. New York: Wiley, [1983]. p. 343-363. 
The origins of Information Science and the International Institute of

Bibliography/International Federation for Information and Documentation (FID). Journal of the American Society for Information Science, [New York], v. 48, n. 4, p. 289-300, 1997.

ROBINSON, L.; BAWDEN, D. 'So wide and varied': the origins and character of British Information Science. Journal of Information Science, [Los Angeles], v. 39, n. 6, p. 754-763, 2013.

SANTOS, B. S. Um discurso sobre as ciências. 16. ed. Porto: Afrontamento, 2010.

SANTOS, P. M. L. O ponto de inflexão Otlet: uma visão sobre as origens da documentação e o processo de construção do Princípio Monográfico. 2006. 138 f. Dissertação (Mestrado em Ciência da Informação) - Escola de Comunicações e Artes, Universidade de São Paulo, São Paulo, 2006.

SCHNEIDERS, P. Bibliografische ondernemingen rond 1900 (deel 1): Eenheid in verscheidenheid. Cahiers de la documentation - Bladen voor documentatie, [Bruxelles], $n$. 2, p. 36-51, 2012a.

Bibliografische ondernemingen rond 1900 (deel 2): De beweging als cultuurhistorisch verschijnsel. Cahiers de la documentation - Bladen voor documentatie, [Bruxelles], n. 3, p. 31-45, 2012b.

De bibliotheek- en documentatiebeweging 1880-1914: bibliografische odernemingen rond 1900. 1982. 254 f. Proefschrift (Graad van doctor in de Letteren)Universiteit van Amsterdam, Amsterdam, 1982.

SHERA, J. H. Special librarianship and documentation. Library Trends, [Urbana], v. 1, n. 2, p. 189-199, 1952.

.; EGAN, M. E. A review of the present state of librarianship and documentation. In: BRADFORD, S. C. Documentation. 2. ed. London: Crosby Lockwood \& Son, 1953. p. 1144.

SMIT, J. W. A informação na Ciência da Informação. InCID: Revista de Ciência da Informação e Documentação, Ribeirão Preto, v. 3, n. 2, p. 84-101, 2012.

TÁLAMO, M. F. G. M.; SMIT, J. W. Ciência da Informação: pensamento informacional e integração disciplinar. Brazilian Journal of Information Science, [Marília], v. 1, n.1, p. 3357, 2007.

TODOROV, T. O espírito das Luzes. São Paulo: Barcarolla, 2008.

WILLIAMS, R. V. The Documentation and special libraries movements in the United States, 1910-1960. Journal of the American Society for Information Science, [New York], v. 48, n. 9, p. 775-781, 1997. 